\title{
Transgender Female Youth and Sex Work: HIV Risk and a Comparison of Life Factors Related to Engagement in Sex Work
}

\author{
Erin C. Wilson · Robert Garofalo · Robert D. Harris • \\ Amy Herrick · Miguel Martinez · Jaime Martinez • \\ Marvin Belzer · The Transgender Advisory Committee \\ and the Adolescent Medicine Trials Network for HIV/AIDS Interventions
}

Published online: 6 February 2009

(C) The Author(s) 2009. This article is published with open access at Springerlink.com

\begin{abstract}
This study examined the HIV risk behaviors and life experiences of 151 transgender female youth, ages 15-24, in Los Angeles and Chicago. Descriptive analyses and logistic regression modeling were used to identify life factors associated with ever having engaged in sex work. Sixty-seven percent of participants had ever engaged in sex work and 19\% self-reported being HIV positive. Many factors were significantly associated with sex work for this sample population. A final multivariate logistic regression model found that lower education status, homelessness, use of street drugs, and perceived social support remained significantly associated with sex work when controlling for other factors. Findings highlight the complex HIV risk environment and suggest a need for sex work initiation research for transgender female youth. HIV prevention
\end{abstract}

E. C. Wilson $(\square)$

Center for AIDS Prevention Studies (CAPS), AIDS Research Institute, University of California, 50 Beale St., Suite 1300,

San Francisco, CA 94105, USA

e-mail: erin.wilson@ucsf.edu

R. Garofalo

Howard Brown Health Center/Children's Memorial Hospital, Chicago, IL, USA

R. D. Harris

Westat, Rockville, MD, USA

\section{A. Herrick}

Howard Brown Health Center, Chicago, IL, USA

M. Martinez $\cdot$ M. Belzer

Division of Adolescent Medicine, Childrens Hospital

Los Angeles, Los Angeles, CA, USA

J. Martinez

Division of Adolescent and Young Adult Medicine,

Stroger Hospital of Cook County, Chicago, IL, USA efforts for this population need to include broad-based approaches that take into account individual, social, and community-level factors relevant to the lives of transgender female youth.

Keywords Youth · Sex work · HIV · Social support · Transgender female youth

\section{Introduction}

Transgender female youth are an understudied, underserved high-risk group for HIV and other STDs. Community partners for this research project coined the term "transgender female youth" to refer to this group of young people by their chosen identity rather than their behavior. Transgender female youth are young people who experience a gender identity that is different from their male anatomic sex at birth. This group of youth has been referred to as Male-to-Female transgender youth in previous literature. Research with transgender women points to high rates of engagement in sex work as a primary contributor to this population's HIV-related sexual risk. A number of urban samples of transgender women have reported high rates of engagement in sex work (ClementsNolle et al. 2001; Kenagy and Hsieh 2005; Nemoto et al. 1999; Simon et al. 2000). For example, a Los Angelesbased study found that sex work was a primary source of recent income for $50 \%$ of its sample of 244 transgender women (Simon et al. 2000).

Regardless of one's sexual or gender identity, individuals that engage in sex work appear to be at increased risk for acquiring HIV through exposure to more sexual partners, dangerous sexual environments, and riskier sex, including the use of substances during sexual encounters 
(Vanwesenbeeck 2001). In fact, a recent literature review found the HIV prevalence among adult transgender female sex workers to be $27.3 \%$ (Operario et al. 2008). Though numerous studies document the relationship between sex work and HIV risk among transgender women, little data exists about this relationship among transgender female youth (Clements-Nolle et al. 2001; Nemoto et al. 2004a, b; Simon et al. 2000; Xavier and Simmons 2000a, b). One Chicago-based pilot study of 51 transgender female youth of color found high rates of exchanging sex for resources (59\% of the sample had a lifetime history of sex work) and HIV positive serostatus (22\% of the sample reported being HIV positive) (Garofalo et al. 2006).

There is also limited research that has explored why transgender women engage in sex work. Much of the literature points to economic hardship due to transphobiadiscrimination specific to transgender people-as a primary reason why transgender women turn to sex work to earn money (Clements-Nolle et al. 2001; Kammerer et al. 1999; Sausa et al. 2007). Transgender women, particularly those who have difficulty "passing," or looking like biologic females, report problems obtaining gainful employment because of transgender-related discrimination (Boles and Elifson 1994; Nemoto et al. 2004a, b). In Garofalo's (2006) pilot study of transgender female youth of color, $61 \%$ reported employment difficulties, which may contribute to the high prevalence of reported sex work within this sample. Another factor particularly salient to transgender female youth may be family rejection. A study by Grossman and D'Augelli (2006) found that rejection by family members was the primary reason many transgender youth reported unstable housing experiences and economic instability, factors which may contribute to initiation into and engagement in sex work. Transgender youth were also found to be vulnerable to participation in sex work due to school dropout resulting from being harassed and discriminated against at school (Grossman and D'Augelli 2006). However, a gap in the literature remains about factors associated with sex work among transgender female youth, leaving providers and interventionists with little guidance as to the best prevention strategies to reduce HIV risk for this vulnerable group of youth.

This analysis used data from the Adolescent Medicine Trials Network-supported Transgender Research Youth Project (TRYP). TRYP was designed to examine the life experiences of transgender female youth in Los Angeles, California and Chicago, Illinois, and to assess their overall risk behaviors. We used these data to address gaps in the literature by examining factors associated with sex work among transgender female youth. We took a social ecological approach to identify factors to be assessed for this analysis (Bronfenbrenner 1979). Social ecological approaches frame human development as shaped by an ongoing interaction between an individual and her social and environmental contexts (Berger and Luckmann 1966; Goffman 1990). This study used a social ecological approach to provide a framework for the research design and analyses in order to better understand this population's life and sex work experiences in a broad context. This approach may help inform the development of targeted HIV or sex work prevention interventions addressing potential mechanisms of risk unique to transgender female youth and their life experiences.

\section{Methods}

TRYP utilized a cross-sectional design to examine the HIV risk behaviors of transgender female youth ages 15-24 in Los Angeles, California, and Chicago, Illinois. We used a community-based participatory research (CBPR) approach to assess the socio-environmental context of risk behaviors, including engagement in sex work, among the transgender female youth in this sample.

Community-Based Participatory Research and the Transgender Advisory Committee

A central tenant of CBPR is partnering with community members on all aspects of a research process to increase the understanding of a health phenomenon in the context of a population's environment (Israel et al. 2005). Studies have shown that community members' insights enhance researchers' understanding of health issues in light of important community dynamics (Higgins and Metzler 2001). For this study, key community members in Los Angeles were invited to serve as a Transgender Advisory Committee (TAC). The TAC was comprised of 12 transgender women who were service providers with experience in HIV prevention and/or transgender health. Transgender female youth representative of our study population also participated in the TAC. Members of the TAC engaged in all aspects of the study, including instrument development, venue identification, recruitment, study monitoring, and data analysis to improve and ensure the quality of the data and the relevance of the study to transgender female youth. TAC members also engaged in a critical discourse to develop the term "transgender female youth," which they felt appropriately focuses on identity rather than behavior when trying to understand the life experiences of this population.

\section{Participants}

The study was conducted in two phases. Phase I, the formative phase of the research, focused on refining the study 
design in collaboration with the TAC. In Phase I, working group discussion sessions with TAC members and the study team from Chicago were conducted to inform instrument development and recruitment strategies. The TAC was instrumental in identifying club/bar venues and street sites where transgender female youth could be recruited. The instruments and recruitment strategies were then piloted with 14 transgender female youth (seven per site). Interviewers took field notes during pilot interviews to guide refinements to the survey instrument and increase clarity and flow. The interviewers also identified venues and street sites where transgender female youth most often congregated during the pilot, which helped the team develop a targeted recruitment strategy for Phase II of the study.

During Phase II, surveys were conducted with 151 transgender female youth, ages 15-24, who lived in Los Angeles $(N=76)$ or Chicago $(N=75)$. Youth were recruited by one of four interviewers. The interview team consisted of two adults and two youth who had worked with transgender female youth in a social service capacity, one of which was a transgender man. Recruitment occurred through word of mouth and flyers posted at health clinics and community-based organizations. Recruitment was also conducted in collaboration with transgender-youth service providers during outreach at club/bar venues and on the street. Effort was made to recruit from street and bar/club venues in order to capture the experiences of youth who might not access social services.

Except for those youth who contacted the study interviewers directly with information from the flyers, the interviewers approached all youth who appeared to be transgender female youth in the targeted age range and asked if they would like to be screened to determine eligibility for participation in the study. A brief screening instrument was developed in collaboration with the TAC and used to assist interviewers in identifying youth who met the criteria for participation. Eligible youths that agreed to participate in the study were administered the face-to-face survey in a safe, confidential, private space either within a venue (e.g., such as a private room in a coffee shop), at a collaborating community-based agency, or at the respective study site. Eligible youth identified as a gender different from their male anatomical sex at birth and lived in the metropolitan area of the respective study site. Interviewers fluent in English and Spanish administered the surveys. Written consent was obtained from all youth 18 years of age and older. Both Institutional Review Boards granted a waiver of parental consent for minors; therefore written assent was obtained for youth $<18$ years of age. All participation was voluntary and confidential. Despite the fact that this is typically a hard-to-reach population, the dedication of the interviewers resulted in finishing the recruitment process in 6 months rather than the 9 months allotted for recruitment.

\section{Measures}

The survey was developed as a compendium of instruments, assessing demographic factors, sexual behaviors, discrimination and stigma, sex work, sexual partnerships and social support.

\section{Dependent Variable}

The dependent variable for this analysis was ever engaging in sex work. Participants were asked: "Have you ever traded sexual activity or favors for food, money, a place to sleep, drugs or other material goods?", with possible response choices of yes, no, or refuse. Participants answering "yes" to this question were considered to have engaged in sex work.

\section{Independent Variables}

(A) Individual-level factors: Demographic variables included age, race/ethnicity, education level completed, income, history of homelessness, and history of incarceration. Participants were also asked questions about age at sexual debut, substance use, and HIV testing. Substance use was coded hierarchically in ascending order from the least adverse effect on sexual risk behavior use of no drugs, to only use of marijuana or alcohol, use of prescription drugs for fun, and finally use of illicit street drugs (Leigh et al. 2008; Stall et al. 2001). Use of street drugs which were considered to have the most potential adverse effect on sexual risk behavior, included crystal methamphetamine, cocaine, heroine, ecstasy, GHB and ketamine (Carey et al. 2008). Finally, youth were asked if they have ever received inpatient services for mental health or substance abuse treatment.

(B) Social-level factors: A global measure of social support was developed based on the 12-item Multidimensional Scale of Perceived Social Support (MSPSS) that was adapted by the TAC for transgender female youth (Zimet et al. 1990). Many lesbian, gay, bisexual, and transgender individuals have what's known as a "family of choice", often made up of close friends, where they get social support normally provided by one's biologic family (Kurdek and Schmitt 1987). Based primarily on TAC recommendations in addition to the literature, we modified the MSPSS by first asking youth from whom they get the most support (parents, chosen family, mentor, 
etc.). The participant's chosen support was then inserted in place of the word "family" for four of the items assessed in the MSPSS. Youth were asked questions like "I can talk about my problems with my [person(s) listed above]." A scaled global social support value was then computed as the sum of the responses to the individual questions; the alpha coefficient for this sample was .9.

(C) Community-level factors: Items assessed participants' experiences of discrimination, personal victimization, and connectedness to the transgender community. Experiences of discrimination were measured as yes/ no responses to youth reports of dropping out of school, not being able to find employment, and getting inappropriate mental health and/or medical care due to their gender identity or gender presentation. A series of questions regarding personal victimization due to perceived transphobia were also assessed by adapting items originally developed by Diaz et al. (2001) for use with the gay community. A victimization scale was constructed as the sum of the responses to ten individual victimization questions. The first five victimization questions asked how often participants experienced various forms of victimization because they were thought to be transgender. For example, youth were asked, "How many times have you been verbally insulted (yelled at, criticized) because you are, or were thought to be, transgender?" In addition, five questions were used to assess the participants' experience with intimate partner violence, including control of their daily activities, being put down, being scared for their personal safety, being physically hurt, and suppressing their gender expression. The alpha coefficient of this ten-item scale for this sample was .8. In addition, connectedness to the transgender community was measured using an adapted version of the Identification and Involvement with the Gay Community Scale (Stall et al. 2001; Stokes et al. 1997; Zimet et al. 1990). The word "transgender" was substituted for the word "gay" on all scale items. For example, youth were asked for a yes/no response to "It is very important to me that at least some of my friends are transgender." Cronbach's alpha for this scale among the sample was .6. Despite the relatively low alpha, this scale was retained in the analysis given the exploratory nature of the investigation and the TAC's request that community connectedness be assessed in this analysis.

\section{Data Analyses}

Univariate statistics (number, percentage, mean, standard deviation [SD], median) were used to describe the characteristics of the study population overall and according to whether or not participants had ever engaged in sex work. Logistic regression modeling was used to assess factors associated with ever engaging in sex work controlling for the effects of age and study site. Factors significantly associated with sex work in these models were included in a multivariate logistic regression model to assess their independent association adjusting for other covariates. Given the large number of statistical tests conducted on the data, a Bonferroni adjustment to the $P$-value was used in identifying variables for inclusion in the final model. Using this approach, variables associated with ever engaging in sex work at the alpha 0.0025 level or lower were included. Study site was included in the model, even though it did not meet this criterion, to adjust for possible heterogeneity by site. There was a high possibility that youth with a history of sex work had been incarcerated due to their engagement in sex work. Therefore, history of incarceration was excluded because findings related to this variable would have been difficult to interpret when trying to differentiate life experiences that may lead to engagement in sex work.

\section{Results}

Table 1 describes characteristics of the overall study population. Sixty-seven percent of the transgender female youth sampled ever engaged in sex work, and $35 \%$ did so in the last 3 months. The study sample ranged from 15 to 24 years of age, with $26 \%$ aged 15-18 years old, $30 \%$ between ages $19-21$, and $44 \%$ between ages $22-24$. Thirtynine percent of the sample identified as African American, $38 \%$ Latina, $5 \%$ White and $18 \%$ as another race or multiracial (consisting of 5\% Asian/Pacific Islanders, .7\% Native American/Alaskan Native, $10 \%$ multi-racial or mixed race, and 3\% "other"). Sixty-seven percent of Latinos/as resided in Los Angeles, while 33\% resided in Chicago. A number of participant characteristics highlighted the economic and interpersonal adversity faced by transgender youth in this sample: $70 \%$ had an income of less than $\$ 1,000$ a month, $43 \%$ had a history of homelessness, $52 \%$ reported having been in the correctional system, and $49 \%$ reported experiencing problems finding employment due to their gender identity or gender presentation. Over $90 \%$ of youths in this sample had used substances, including alcohol or drugs during their lifetimes (alcohol 88\%, marijuana 63\%, cocaine 30\%, ecstasy $32 \%$ and methamphetamine $30 \%$ ). Eighty-seven percent of youth had been tested for HIV at least once. Nineteen percent of participants self-reported being HIV positive.

Table 1 also shows the distribution of characteristics of youth participants according to whether or not they had 
Table 1 Characteristics of transgender female youth overall and according to whether or not participants ever engaged in sex work and logistic regression modeling results of the association of these characteristics with a history of sex work

\begin{tabular}{|c|c|c|c|c|c|}
\hline \multirow[t]{2}{*}{ Characteristic } & \multirow[t]{2}{*}{ Overall } & \multicolumn{2}{|c|}{ Ever engaged in sex work } & \multicolumn{2}{|c|}{ Logistic regression results } \\
\hline & & $\begin{array}{l}\text { Yes } \\
(N=101)\end{array}$ & $\begin{array}{l}\text { No } \\
(N=50)\end{array}$ & OR & $\begin{array}{l}95 \% \text { Confidence } \\
\text { interval }\end{array}$ \\
\hline \multicolumn{6}{|l|}{ Individual level factors } \\
\hline \multicolumn{6}{|l|}{ Demographics } \\
\hline \multicolumn{6}{|l|}{ Study site: } \\
\hline Los Angeles, CA & $76(50)$ & $57(56)$ & $19(38)$ & 2.11 & $(1.06,4.23)^{*}$ \\
\hline Chicago, IL & $75(50)$ & $44(44)$ & $31(62)$ & & \\
\hline \multicolumn{6}{|l|}{ Age: (in years) } \\
\hline Median & 21 & 21 & 21 & 1.15 & $(0.88,1.51)^{\mathrm{a}}$ \\
\hline 15-18 years old & $39(26)$ & $25(25)$ & $14(28)$ & & \\
\hline 19-21 years old & $45(30)$ & $28(28)$ & $17(34)$ & & \\
\hline $22-24$ years old & $67(44)$ & $48(48)$ & $19(38)$ & & \\
\hline \multicolumn{6}{|l|}{ Race/ethnicity: } \\
\hline White & $7(5)$ & $1(1)$ & $6(12)$ & 0.15 & $(0.02,1.44)$ \\
\hline African American & $59(39)$ & $41(41)$ & $18(36)$ & 2.34 & $(0.89,6.18)$ \\
\hline Latino/a & $58(38)$ & $45(45)$ & $13(26)$ & 2.82 & $(1.04,7.68)^{*}$ \\
\hline Other non-white & $27(18)$ & $14(14)$ & $13(26)$ & & \\
\hline \multicolumn{6}{|l|}{ Highest level of education completed: $n(\%)$} \\
\hline Less than high school graduate & $59(39)$ & $46(46)$ & $13(26)$ & 4.53 & $(1.78,11.53)^{* *}$ \\
\hline High school graduate/GED or greater & $92(61)$ & $55(54)$ & $37(74)$ & & \\
\hline \multicolumn{6}{|l|}{ Total income during the past 30 days: } \\
\hline None or $<\$ 50(<\$ 600$ per year $)$ & $19(13)$ & $13(13)$ & $6(12)$ & & \\
\hline$\$ 51-\$ 249(\$ 600-\$ 2,999)$ & $27(18)$ & $18(18)$ & $9(18)$ & 0.91 & $(0.25,3.29)$ \\
\hline$\$ 250-\$ 499(\$ 3,000-\$ 5,999)$ & $21(14)$ & $14(14)$ & $7(14)$ & 1.06 & $(0.27,4.18)$ \\
\hline$\$ 500-\$ 999(\$ 6,000-\$ 11,999)$ & $37(25)$ & $20(20)$ & $17(34)$ & 0.54 & $(0.16,1.85)$ \\
\hline$\$ 1,000-\$ 2,999(\$ 12,000$ to $\geq \$ 60,000$ a year $)$ & $45(30)$ & $34(34)$ & $11(22)$ & 1.29 & $(0.36,4.57)$ \\
\hline Don't know & 2 & 2 & 0 & & \\
\hline
\end{tabular}

Homelessness: Ever spent one or more nights in emergency shelter, transitional housing facility, welfare hotel or a public/private place not designed for sleeping: $n(\%)$

\begin{tabular}{|c|c|c|c|c|c|}
\hline Yes & $65(43)$ & $55(55)$ & $10(20)$ & 4.42 & $(1.95,10.07)^{* *}$ \\
\hline No & $85(57)$ & $45(45)$ & $40(80)$ & & \\
\hline Refused to answer & 1 & 1 & 0 & & \\
\hline
\end{tabular}

Ever been in the correctional system: $n(\%)$

$\begin{array}{llllll}\text { Yes } & 78(52) & 65(64) & 13(26) & 6.08 & (2.74,13.53) * * \\ \text { No } & 73(48) & 36(36) & 37(74) & \end{array}$

Ever been placed in inpatient program (alcohol treatment, mental health inpatient facility): $n(\%)$

\begin{tabular}{|c|c|c|c|c|c|}
\hline Yes & $39(26)$ & $34(34)$ & $5(10)$ & 4.35 & $(1.57,12.10)^{* * *}$ \\
\hline No & $111(74)$ & $66(66)$ & $45(90)$ & & \\
\hline Refused to answer & 1 & 1 & 0 & & \\
\hline
\end{tabular}

Sexual debut

At what age did participant first have vaginal, oral or anal sex because you wanted to:
Median
15.0
14.0
16.0
0.95
$(0.86,1.04)^{\mathrm{b}}$

Substance use

Highest level of drugs reported to have ever been used:

$\begin{array}{llllll}\text { Street drugs } & 78(52) & 68(69) & 10(20) & 8.95 & (2.22,36.06)^{* * *} \\ \text { Marijuana or alcohol } & 59(40) & 26(26) & 33(66) & 1.06 & (0.29,3.85) \\ \text { No drugs } & 12(8) & 5(5) & 7(14) & & \end{array}$


Table 1 continued

\begin{tabular}{|c|c|c|c|c|c|}
\hline \multirow[t]{2}{*}{ Characteristic } & \multirow[t]{2}{*}{ Overall } & \multicolumn{2}{|c|}{ Ever engaged in sex work } & \multicolumn{2}{|c|}{ Logistic regression results } \\
\hline & & $\begin{array}{l}\text { Yes } \\
(N=101)\end{array}$ & $\begin{array}{l}\text { No } \\
(N=50)\end{array}$ & OR & $\begin{array}{l}95 \% \text { Confidence } \\
\text { interval }\end{array}$ \\
\hline \multicolumn{6}{|l|}{ HIV testing } \\
\hline \multicolumn{6}{|l|}{ Ever been tested for HIV: $n(\%)$} \\
\hline Yes, more than once & $110(74)$ & $84(85)$ & $26(52)$ & 16.16 & $(4.66,56.09)^{* *}$ \\
\hline Yes, once & $19(13)$ & $11(11)$ & $8(16)$ & 7.77 & $(1.73,34.89)$ \\
\hline No & $20(13)$ & $4(4)$ & $16(32)$ & & \\
\hline Don't know/Refused to answer & 2 & 2 & 0 & & \\
\hline HIV testing rate per 100 subjects & 86.6 & 96.0 & 68.0 & & \\
\hline \multicolumn{6}{|c|}{ What were results of last HIV test: $n(\%)$} \\
\hline HIV positive & $24(19)$ & $22(23)$ & $2(6)$ & 4.46 & $(0.97,20.49)$ \\
\hline HIV negative & $103(81)$ & $72(77)$ & $31(94)$ & & \\
\hline Never went back for results & 1 & 1 & 0 & & \\
\hline Don't know results of last test & 1 & 0 & 1 & & \\
\hline \multicolumn{6}{|l|}{ Social level factors } \\
\hline \multicolumn{6}{|l|}{ Social support } \\
\hline \multicolumn{6}{|l|}{ Perceived social support: } \\
\hline Mean (SD) & $16.2(6.8)$ & $17.7(7.2)$ & $13.3(4.9)$ & 1.78 & $(1.27,2.48)^{\mathrm{c}, * *}$ \\
\hline Median & 15.0 & 16.0 & 13.5 & & \\
\hline \multicolumn{6}{|l|}{ Community level factors } \\
\hline \multicolumn{6}{|l|}{ Discrimination } \\
\hline \multicolumn{6}{|c|}{ Ever experienced problems getting a job because of gender identity or gender presentation: $n(\%)$} \\
\hline Yes & $71(49)$ & $52(55)$ & $19(39)$ & 1.87 & $(0.89,3.92)$ \\
\hline No & $73(51)$ & $43(45)$ & $30(61)$ & & \\
\hline Don’t know/Refused to answer & 7 & 6 & 1 & & \\
\hline \multicolumn{6}{|c|}{ Ever had to drop out of school because of gender identity or gender presentation: $n(\%)$} \\
\hline Yes & $36(24)$ & $30(30)$ & $6(12)$ & 3.89 & $(1.44,10.52)^{* *}$ \\
\hline No & $114(76)$ & $70(70)$ & $44(88)$ & & \\
\hline Refused to answer & 1 & 1 & 0 & & \\
\hline \multicolumn{6}{|l|}{ Victimization } \\
\hline \multicolumn{6}{|l|}{ Victimization scale: } \\
\hline Median & 35.0 & 48.0 & 29.0 & 1.05 & $(0.99,1.12)^{\mathrm{d}}$ \\
\hline \multicolumn{6}{|l|}{ Community connectedness } \\
\hline \multicolumn{6}{|c|}{ Identification with the transgender community: } \\
\hline Mean (SD) & $6.6(3.0)$ & $6.5(2.8)$ & $7.0(3.3)$ & 0.98 & $(0.77,1.24)^{\mathrm{e}}$ \\
\hline Median & 6.0 & 6.8 & 6.0 & & \\
\hline
\end{tabular}

Notes: The variables in Italics are the referent group. Also, the significance of associations between characteristics and history of engagement in sex work (ever engaged in sex work vs. never engaged in sex work) were assessed using logistic regression models adjusting for possible age and site differences

${ }^{a}$ The odds ratio for age is computed relative to a 2 year increase in age

b The odds ratio for age at which participant first had vaginal, oral or anal sex because they wanted to is computed relative to a 1 year increase

c The odds ratio for perceived social support is computed relative to a 5 unit increase in the scale

d The odds ratio for victimization is computed relative to a 100 unit increase in the scale

e The odds ratio for Identification with the transgender community is computed relative to a 1 unit increase in the scale

$* P<0.05$

** $P<0.01$ 
ever engaged in sex work, and shows results examining the significance of the association of these factors with history of sex work, controlling for the effects of age and study site. Although age was not significantly associated with history of sex work in the presence of study site, it was nevertheless included in the models given the wide range in age of the study participants and the possible influence that age might have on the characteristics being examined. Study site was significantly associated with sex work, adjusted for possible differences in age $(P<.05)$. The odds of sex work engagement among youth from Los Angeles were more than two times the odds of youth from Chicago (odds ratio $[\mathrm{OR}]=2.11,95 \%$ confidence interval $[\mathrm{CI}]=1.06-4.23$ ).

A number of the individual characteristics were found to be associated with sex work among study participants. After controlling for the effects of age and study site, race/ ethnicity was significantly associated with ever engaging in sex work $(P<.05)$; the majority of participants reporting engagement in sex work were African American and Latino/a (41 and 45\%, respectively), but only Latinos/as differed significantly from other non-whites. Since only one of seven White participants had ever engaged in sex work, it was not possible to use White as the reference group for modeling. Instead we used a group we named "other non-whites," which consisted of individuals identifying as Asian Pacific Islanders, Native Americans/ Alaskan Natives, Multi-racial, and "other" as the reference group. Individual-level factors of less than a high school education $(\mathrm{OR}=4.53,95 \% \mathrm{CI}=1.78-11.53)$, history of homelessness (OR $=4.42,95 \% \mathrm{CI}=1.95-10.07)$, having been in the correctional system $(\mathrm{OR}=6.08,95 \%$ $\mathrm{CI}=2.74-13.53$ ), having ever been in an inpatient program $(\mathrm{OR}=4.35,95 \% \mathrm{CI}=1.57-12.10)$, and street drug use $(\mathrm{OR}=8.95,95 \% \mathrm{CI}=2.22-36.06)$ were each positively and significantly associated with sex work (all $P$-values $<0.01$ ). Ninety-six percent of participants who had engaged in sex work had been tested for HIV at least once, compared to $68 \%$ of participants who had not engaged in sex work. The odds of ever having engaged in sex work was significantly greater among those who had been tested for HIV once $(\mathrm{OR}=7.77,95 \% \mathrm{CI}=1.73$, 34.89 ) or more than once $(\mathrm{OR}=16.16,95 \% \mathrm{CI}=4.66$, 56.09) compared to those who had never been tested $(P<0.01)$. Twenty-three percent of youth with a history of sex work reported being HIV positive compared to only $6 \%$ among those who never engaged in sex work; the odds of ever having engaged in sex work was over four times higher among HIV positive than HIV negative participants, but this association was only of borderline significance, controlling for age and study site $(P=0.054)$. Among the social and community-level factors that were examined, perceived social support, treated as a continuous measure, was also significantly and positively associated with engagement in sex work $(P<0.01)$. The odds of engaging in sex work increased with increased perceived social support. Dropping out of school due to gender identity or gender presentation was also positively associated with sex work $(\mathrm{OR}=3.89,95 \% \mathrm{CI}=1.44-10.52 ; P<.01)$.

Table 2 describes the final adjusted multivariate logistic regression model fit to the data to determine which variables remained independently associated with ever engaging in sex work after adjusting for the other significant variables included in the model. The final model included study site, highest education level completed, homelessness, highest level of drugs ever used, and
Table 2 Multivariate investigation of association of selected variables with history of engaging in sex work using logistic regression modeling

Note: The variables in Italics are the referent group

$* P \leq 0.05$

** $P \leq 0.01$

\begin{tabular}{|c|c|c|}
\hline Variable & OR & 95\% Confidence interval \\
\hline \multicolumn{3}{|l|}{ Study site: } \\
\hline Los Angeles, CA & 1.27 & $(0.32,3.17)$ \\
\hline \multicolumn{3}{|l|}{ Chicago, IL } \\
\hline \multicolumn{3}{|l|}{ Highest educational level completed: } \\
\hline Less than high school graduate & 2.87 & $(1.11,7.41)^{*}$ \\
\hline \multicolumn{3}{|c|}{ High school graduate/GED or greater } \\
\hline \multicolumn{3}{|c|}{$\begin{array}{l}\text { Homelessness: Ever spent one or more nights in emergency shelter, transitional housing facility, welfare } \\
\text { hotel or a public/private place not designed for sleeping: }\end{array}$} \\
\hline Yes & 4.17 & $(1.55,11.24)^{* *}$ \\
\hline \multicolumn{3}{|l|}{ No } \\
\hline \multicolumn{3}{|c|}{ Highest level of drugs reported to have ever been used: } \\
\hline Street drugs & 15.10 & $(2.96,77.17)^{* *}$ \\
\hline Marijuana or alcohol & 2.18 & $(0.46,10.34)$ \\
\hline \multicolumn{3}{|l|}{ No drugs } \\
\hline \multicolumn{3}{|l|}{ Perceived social support: } \\
\hline 5 unit increase & 1.97 & $(1.31,2.98)^{* *}$ \\
\hline
\end{tabular}


perceived social support. The odds of ever engaging in sex work was significantly higher among those with less than a high school education, those who had ever been homeless, and those who used street drugs (vs. no substance use). A five-unit increase in the perceived social support scale was associated with nearly a twofold increase in the odds of engaging in sex work.

\section{Discussion}

Consistent with emerging literature on transgender women, this analysis showed that both sex work and HIV were highly prevalent in this sample of transgender female youth. In addition, this study found a number of individual, social, and community-level factors that were associated with sex work among the transgender female youth sampled. Understanding the relationship between these complex variables, sex work, and HIV-related sexual risk will help in the design of uniquely tailored prevention efforts that are needed for this well-known high-risk group of youth.

Among the individual-level variables, youth participants with a history of sex work had significantly lower education attainment, more homelessness, and were more likely to have been incarcerated in comparison to peers without a history of sex work. In addition, transgender female youth with a history of sex work were more likely to have been treated in inpatient mental health or substance abuse programs. For these youth, the inpatient care services may have been obtained for behaviors or conditions that were a precursor to sex work, but could also signify youth who were institutionalized as a result of substance abuse and mental health issues that can arise from engaging in sex work (Bockting et al. 1998).

The overall HIV prevalence within the sample was $19 \%$, notably higher than the prevalence reported in other youth study samples. Research with a nationally representative sample of youth ages 18-28 found the HIV rate to be only 1 per 1,000 (Morris et al. 2006). Our findings are more consistent with results from the Young Men's Survey (YMS), a multi-site CDC-funded HIV prevalence study of young men ages 15-22 who have sex with men that revealed an overall HIV prevalence of $7.2 \%$, ranging from $3.3 \%$ among Whites to $6.9 \%$ among Latinos, and $14.1 \%$ among African American young men who have sex with men (YMSM). Of note, the transgender-identified YMSM in the YMS had a HIV prevalence of $14 \%$ (Valleroy et al. 2000). Rates of HIV found within this sample were also more akin to the high rates of HIV found among samples of transgender women reported in a variety of small, nonrepresentative samples that range from 22 to $35 \%$ (Clements-Nolle et al. 2001; Nemoto et al. 2004a, b; Simon et al. 2000; Xavier and Simmons 2000a, b.
A possible link between HIV and sex work among transgender female youth was also identified in this study. Youth with a history of sex work were more than four times as likely to have HIV as their peers without such a history. The reported HIV rate among transgender female youth in this sample with a history of sex work is concerning (23\%). The potential link between HIV and sex work shown in these data is similar to findings among adult transgender female sex workers (Operario et al. 2008). The finding that at this very young age many of these transgender female youth are either already HIV positive or are actively engaged in sex work signals a need for intervention efforts that commence earlier in the life trajectories of transgender women in order to stop the pervasive spread of the disease within this community.

One unanticipated finding was that transgender female youth with a history of sex work were also more likely to report having a higher perceived level of social support. However, the association of engaging in sex work with the discrimination was anticipated. Youth with a history of sex work were more likely to report having experienced discrimination in school settings than youth without a history of sex work.

The final model for this analysis helped determine which of the many significant variables remained independently associated with engagement in sex work for this sample of transgender female youth. Education attainment, history of homelessness, drug use, and social support remained significantly associated with engagement in sex work. The importance of homelessness as a correlate of sex work is heavily supported in the non-transgender youth literature. Much research points to homelessness and runaway behavior as precursors to engagement in sex work among young people (Dalla 2006; Weber et al. 2004). Though directionality cannot be determined through this cross sectional study, it is likely that unstable housing situations and other components of economic instability led to engagement in sex work for many of the youth sampled. Substance use remained a highly significant correlate of sex work within this sample, which is again consistent with findings from samples of transgender women (Clements-Nolle et al. 2001; Nemoto et al. 2004a, b; Operario and Nemoto 2005). The association between sex work and substance use may be related to a number of factors. Substance use may occur as a way to cope with the stressor of engaging in sex work, as has been reported in research with transgender women (Bockting et al. 1998). Alternatively, substance use may lead to risky situations wherein sex work was initiated (Sausa et al. 2007). Since sex work was defined in this study as trading sex for food, money, a place to sleep, drugs or other material goods, it may also be possible that youth exchanged sex specifically for drugs. 
The finding that transgender female youth with a history of sex work were also more likely to report having a higher perceived level of social support was provocative. To our knowledge, there is no research about transgender female youth, sex work, and social support with which these findings can be compared. These findings are in contrast to existing literature with non-transgender-identified homeless youth that shows low social support linked to engagement in sex work (Ennett et al. 1999).

The TAC advised the research team that because of family rejection, many transgender female youth have alternative forms of social support. Therefore, questions assessing social support should first ask participants to identify who is their primary support, instead of asking exclusively about family, and then ask questions about the participant-defined primary support system. This recommendation was supported by research showing that it is relatively common for gay, lesbian, bisexual, and transgender individuals to find alternative social support systems due to rejection they face from biologic family members (Grossman and D'Augelli 2006; Jacobs et al. 1999; Kurdek and Schmitt 1987). The way the social support items were re-configured resulted in some youth inserting other members of the transgender community in place of the word "family" for those survey questions. In keeping with the CBPR approach, the research team used the TAC-recommended social support questions. We realized that the way in which questions were asked may have biased results towards high social support being linked with sex work because "family support" was not explicitly assessed for many youth, and a number of youth reported other transgender women as their "family" or primary sources of support. Our social support measurement instrument may have been skewed to more accurately reflect those alternative support systems. However, a significant difference in social support between youth with a history of sex work and those without remained regardless of how the questions were asked.

The association we found between higher social support and engagement in sex work may reflect that some youth participants found a unique source of support within the transgender sex work community. This conjecture is consistent with research observing that transgender women often find community on the street where they are introduced to sex work, and report this form of support as affirming of their female gender identity and supportive in providing a connection to other transgender women (Bockting et al. 1998). Sausa et al. (2007) similarly found that the social network among sex workers provided an important form of social support that often replaced nonexistent family support and aided in the process of transitioning for many transgender women. In light of these data, interventionists should consider how to utilize the network among transgender female sex workers to promote health and advance HIV prevention for transgender female youth. Interventionists should also consider finding or creating other sources of community for transgender female youth. Though there are noted benefits that have arisen from connections to sex work networks among transgender women, these networks are still problematic because they are part of a risky HIV environment. Therefore, it would be beneficial for transgender female youth to have alternative sources of support and community. Interventions focused on community building and developing spaces for transgender female youth that provide social support and exposure to healthy environments may provide an important alternative to sex work networks. Additionally, research may be needed to better understand how social support influences sex work practices and HIV risk behaviors, including how these networks affect-positively or negatively-HIV-related risk behavior.

Despite the many risks identified by these data, this study also found that transgender female youth, especially those with a history of sex work, are getting tested for HIV at high rates. Knowing one's HIV status has been linked to reduced risk behaviors for HIV positive individuals, which may also be the case for transgender female youth (Branson et al. 2006). HIV testing also provides a critical clinical opportunity for providers to reach both those transgender female youth who engage in sex work and those who may not with prevention messages and other intervention strategies (Marks et al. 2005). Lastly, youths with a history of sex work that are interested in knowing their HIV status may be likely to enter treatment and care early if found to be HIV positive, which may also be an important secondary prevention strategy for HIV positive individuals (Branson et al. 2006).

A number of limitations should be considered when interpreting the findings of this study. Data were drawn from two urban centers using a convenience sampling framework that included recruiting youth accessing HIV prevention and treatment services at clinic sites. The most stigmatized individuals within this group may have been those who study staff could not access. As such, our findings may not generalize to a more diverse sample of youth, including transgender female youth who do not live in urban areas. The cross-sectional nature of the data collection does not allow us to determine whether or not some of the associated variables served as precursors or rather were the result of engagement in sex work. Another important limitation is that we considered youth with a history of sex work as those who had "ever engaged in sex work" for the analysis. We used the more inclusive variable of "ever engaged in sex work," instead of assessing those who had engaged in sex work in the last 3 months, in order to get a better understanding of the entire population who engaged 
in sex work. Because this categorization may have included youth with a range of experience with sex work, there may be great variability in the group we characterized as "youth with a history of sex work." Also, data gathered about transgender community connectedness may not have captured the true construct of interest due to the low alpha for the scale developed. This scale was retained in the analysis in deference to our TAC and the exploratory nature of the research. The data was also collected by self-report, and as with all studies collecting sensitive personal information, the social desirability of answers given by transgender female youth participants may be a concern. However, selfreported data is often reliable with youth samples (Shew et al. 1997). And participants were interviewed by peers or experienced service providers in an effort to make youth comfortable giving accurate information about risk behavior, thereby hopefully reducing socially desirable responses. Despite these limitations, to our knowledge this is the first two-site study to examine sex work and HIVrelated sexual risk in a young, ethnically diverse sample of transgender female youth, who are a well-known high-risk group for the acquisition of HIV.

\section{Conclusions}

Interventions that focus on youth development are imminently needed for reducing initiation and engagement in sex work and HIV risk among transgender female youth. Prevention programs targeting this population should take into consideration the developmental needs that may be unique to female youth who are transgender. Program activities that focus on encouraging normal adolescent development within a transgender paradigm would make an important contribution to an intervention focusing on sex work prevention among transgender female youth. Additionally, programs that help youth develop healthy alternative and traditional sources of social support, find safe and affordable housing options, and complete their education may be needed to fill gaps in the complex environmental context of HIV risk for this population.

This study also has implications for future research. Though each of the factors significant in this study is important individually, researchers should consider examining engagement in sex work in terms of co-occurring factors. The final model for this analysis speaks to the need for research that considers taking a syndemics approach to the collection and analysis of data, wherein factors are assessed for their additive contribution to HIV risk (Mustanski et al. 2007). For example, homelessness alone my not fully explain why some transgender female youth engage in sex work. However, the cluster or co-occurrence of factors such as lack of education, homelessness, and substance use may help to better explain the circumstances under which transgender female youth initiate into sex work. These results also further highlight the complex risk environment that is a reality for many transgender female youth, and support the broader environmental approach taken in this study. Although not specifically examined in this study, for many transgender female youth sex workers, sex work serves the dual role of helping to achieve an otherwise elusive economic viability, while simultaneously validating a much-desired female gender identity (Garofalo et al. 2007). Therefore, sex work can be challenging to avoid, thereby making sex work and HIV prevention interventions particularly complex.

Finally, in addition to risk, it is important that researchers and providers focus some attention on resiliency, or protective strategies at-risk transgender female youth employ to reduce their risk for HIV. The finding that transgender female youth are aware of their risks for HIV, as exhibited by the high HIV testing rates, speaks to a willingness to participate in risk reduction behaviors. Few other communities have been shown to have such high HIV testing rates, and researchers and providers are encouraged to build upon the strengths identified in this study.

Acknowledgments The Adolescent Trials Network for HIV/AIDS Interventions (ATN) is funded by grant No. U01 HD40533 from the National Institutes of Health through the National Institute of Child Health and Human Development (A. Rogers, L. Serchuck), with supplemental funding from the National Institutes on Drug Abuse (N. Borek), Mental Health (A. Forsyth, P. Brouwers), and Alcohol Abuse and Alcoholism (K. Bryant). We acknowledge the contribution of the investigators and staff at the following ATN sites that participated in this study: Children's Memorial Hospital, Chicago (R. Garofalo); and Children's Hospital of Los Angeles, Los Angeles, CA (M. Belzer). The study was scientifically reviewed by the ATN's Behavioral Leadership Group. Network scientific and logistical support was provided by the ATN Coordinating Center (C. Wilson, C. Partlow), at University of Alabama at Birmingham. Network operations and analytic support was provided by the ATN Data and Operations Center at Westat, Inc., (J. Korelitz, B. Driver). The investigators are grateful to the members of the Transgender Advisory Committee for their insight and counsel and are particularly indebted to the youth who participated in this study. We also acknowledge Gary Harper who served as a consultant on this project.

Open Access This article is distributed under the terms of the Creative Commons Attribution Noncommercial License which permits any noncommercial use, distribution, and reproduction in any medium, provided the original author(s) and source are credited.

\section{References}

Berger, P., \& Luckmann, T. (1966). The social construction of reality. London: Allan Lane.

Bockting, W. O., Robinson, B. E., \& Rosser, B. R. (1998). Transgender HIV prevention: A qualitative needs assessment. AIDS Care, 10, 505-525. doi:10.1080/09540129850124028. 
Boles, J., \& Elifson, K. W. (1994). The social organization of transvestite prostitution and AIDS. Social Science and Medicine, 39, 85-93. doi:10.1016/0277-9536(94)90168-6.

Branson, B. M., Handsfield, H. H., Lampe, M. A., Janssen, R. S., Taylor, A. W., Lyss, S. B., et al. (2006). Revised recommendations for HIV testing of adults, adolescents, and pregnant women in health-care settings. Morbidity and mortality weekly report. Recommendations and reports, 55, 1-17. quiz CE11-14.

Bronfenbrenner, U. (1979). The ecology of human development: Experiments by nature and design. Cambridge: Harvard University Press.

Carey, J.W., Mejia, R., Bingham, T., Ciesielski, C., Gelaude, D., Herbst, J.H., et al. (2008). Drug use, high-risk sex behaviors, and increased risk for recent HIV infection among men who have sex with men in Chicago and Los Angeles [Electronic Version]. AIDS and Behavior. Retrieved May 23 from http://www.ncbi. nlm.nih.gov/entrez/query.fcgi? $\mathrm{cmd}=$ Retrieve $\& \mathrm{db}=$ PubMed $\&$ $\mathrm{dop} t=$ Citation\&list_uids $=18498049$.

Clements-Nolle, K., Marx, R., Guzman, R., \& Katz, M. (2001). HIV prevalence, risk behaviors, health care use, and mental health status of transgender persons: Implications for public health intervention. American Journal of Public Health, 91, 915-921. doi:10.2105/AJPH.91.6.915.

Dalla, R. (2006). "You can't hustle all your life": An exploratory investigation of the exit process among street-level prostituted women. Psychology of Women Quarterly, 33, 276-290. doi: 10.1111/j.1471-6402.2006.00296.x.

Diaz, R. M., Ayala, G., Bein, E., Henne, J., \& Marin, B. V. (2001). The impact of homophobia, poverty, and racism on the mental health of gay and bisexual Latino men: Findings from 3 US cities. American Journal of Public Health, 91, 927-932. doi: 10.2105/AJPH.91.6.927.

Ennett, S. T., Bailey, S. L., \& Federman, E. B. (1999). Social network characteristics associated with risky behaviors among runaway and homeless youth. Journal of Health and Social Behavior, 40, 63-78. doi:10.2307/2676379.

Garofalo, R., Deleon, J., Osmer, E., Doll, M., \& Harper, G. W. (2006). Overlooked, misunderstood and at-risk: Exploring the lives and HIV risk of ethnic minority male-to-female transgender youth. The Journal of Adolescent Health, 38, 230-236. doi: 10.1016/j.jadohealth.2005.03.023.

Garofalo, R., Herrick, A., Mustanski, B. S., \& Donenberg, G. R. (2007). Tip of the iceberg: Young men who have sex with men, the Internet, and HIV risk. American Journal of Public Health, 97, 1113-1117. doi:10.2105/AJPH.2005.075630.

Goffman, E. (1990). Stigma-notes on the management of spoiled identity (3rd ed.). London: Penguin.

Grossman, A. H., \& D'Augelli, A. R. (2006). Transgender youth: Invisible and vulnerable. Journal of Homosexuality, 51, 111128. doi:10.1300/J082v51n01_06.

Higgins, D. L., \& Metzler, M. (2001). Implementing communitybased participatory research centers in diverse urban settings. Journal of Urban Health, 78, 488-494. doi:10.1093/jurban/ 78.3.488

Israel, B. A., Parker, E. A., Rowe, Z., Salvatore, A., Minkler, M., Lopez, J., et al. (2005). Community-based participatory research: Lessons learned from the Centers for Children's Environmental Health and Disease Prevention Research. Environmental Health Perspectives, 113, 1463-1471.

Jacobs, R., Rasmussen, L., \& Hohman, M. (1999). The social support needs of older lesbians, gay men, and bisexuals. Journal of Gay \& Lesbian Social Services, 9, 1-30. doi:10.1300/J041v09n01_01.

Kammerer, N., Mason, T., \& Connors, M. (1999). Transgender Health and Social Service needs in the context of HIV Risk. International Journal of Transgenderism, 3.
Kenagy, G. P., \& Hsieh, C. M. (2005). The risk less known: Femaleto-male transgender persons' vulnerability to HIV infection. AIDS Care, 17, 195-207. doi:10.1080/19540120512331325680.

Kurdek, L. A., \& Schmitt, J. P. (1987). Perceived emotional support from family and friends in members of homosexual, married, and heterosexual cohabiting couples. Journal of Homosexuality, 14, 57-68. doi:10.1300/J082v14n03_04.

Leigh, B. C., Vanslyke, J. G., Hoppe, M. J., Rainey, D. T., Morrison, D. M., \& Gillmore, M. R. (2008). Drinking and condom use: Results from an event-based daily diary. AIDS and Behavior, 12, 104-112. doi:10.1007/s10461-007-9216-9.

Marks, G., Crepaz, N., Senterfitt, J. W., \& Janssen, R. S. (2005). Meta-analysis of high-risk sexual behavior in persons aware and unaware they are infected with HIV in the United States: Implications for HIV prevention programs. Journal of Acquired Immune Deficiency Syndromes, 39, 446-453. doi:10.1097/01.qai. 0000151079.33935 .79 .

Morris, M., Handcock, M. S., Miller, W. C., Ford, C. A., Schmitz, J. L., Hobbs, M. M., et al. (2006). Prevalence of HIV infection among young adults in the United States: Results from the Add Health study. American Journal of Public Health, 96, 10911097. doi:10.2105/AJPH.2004.054759.

Mustanski, B., Garofalo, R., Herrick, A., \& Donenberg, G. (2007). Psychosocial health problems increase risk for HIV among urban young men who have sex with men: Preliminary evidence of a syndemic in need of attention. Annals of Behavioral Medicine, 34, 37-45. doi:10.1007/BF02879919.

Nemoto, T., Iwamoto, M., Wong, S., Le, M. N., \& Operario, D. (2004a). Social factors related to risk for violence and sexually transmitted infections/HIV among Asian massage parlor workers in San Francisco. AIDS and Behavior, 8, 475-483. doi: 10.1007/s10461-004-7331-4.

Nemoto, T., Luke, D., Mamo, L., Ching, A., \& Patria, J. (1999). HIV risk behaviours among male-to-female transgenders in comparison with homosexual or bisexual males and heterosexual females. AIDS Care, 11, 297-312. doi:10.1080/09540129947938.

Nemoto, T., Operario, D., Keatley, J., Han, L., \& Soma, T. (2004b). HIV risk behaviors among male-to-female transgender persons of color in San Francisco. American Journal of Public Health, 94, 1193-1199.

Operario, D., \& Nemoto, T. (2005). Sexual risk behavior and substance use among a sample of Asian Pacific Islander transgendered women. AIDS Education and Prevention, 17, 430-443. doi:10.1521/aeap2005.17.5.430.

Operario, D., Soma, T., \& Underhill, K. (2008). Sex work and HIV status among transgender women: Systematic review and metaanalysis. Journal of Acquired Immune Deficiency Syndromes, 48, 97-103. doi:10.1097/QAI.0b013e31816e3971.

Sausa, L. A., Keatley, J., \& Operario, D. (2007). Perceived risks and benefits of sex work among transgender women of color in San Francisco. Archives of Sexual Behavior, 36, 768-777. doi: 10.1007/s10508-007-9210-3.

Shew, M. L., Remafedi, G. J., Bearinger, L. H., Faulkner, P. L., Taylor, B. A., Potthoff, S. J., et al. (1997). The validity of self-reported condom use among adolescents. Sexually Transmitted Diseases, 24, 503-510. doi:10.1097/00007435-199710000-00002.

Simon, P. A., Reback, C. J., \& Bemis, C. C. (2000). HIV prevalence and incidence among male-to-female transsexuals receiving HIV prevention services in Los Angeles Country. AIDS (London, England), 14, 2953-2955. doi:10.1097/00002030-200012220-00024.

Stall, R., Paul, J. P., Greenwood, G., Pollack, L. M., Bein, E., Crosby, G. M., et al. (2001). Alcohol use, drug use and alcohol-related problems among men who have sex with men: The Urban Men's Health Study. Addiction (Abingdon, England), 96, 1589-1601. doi:10.1046/j.1360-0443.2001.961115896.x. 
Stokes, J. P., Vanable, P., \& McKirnan, D. J. (1997). Comparing gay and bisexual men on sexual behavior, condom use, and psychosocial variables related to HIV/AIDS. Archives of Sexual Behavior, 26, 383-397. doi:10.1023/A:1024539301997.

Valleroy, L. A., MacKellar, D. A., Karon, J. M., Rosen, D. H., McFarland, W., Shehan, D. A., et al. (2000). HIV prevalence and associated risks in young men who have sex with men. Young Men's Survey Study Group. Journal of the American Medical Association, 284, 198-204. doi:10.1001/jama.284.2.198.

Vanwesenbeeck, I. (2001). Another decade of social scientific work on sex work: A review of research 1990-2000. Annual Review of Sex Research, 12, 242-289.

Weber, A. E., Boivin, J. F., Blais, L., Haley, N., \& Roy, E. (2004). Predictors of initiation into prostitution among female street youths. Journal of Urban Health, 81, 584-595. doi:10.1093/ jurban/jth142.

Xavier, J., \& Simmons, R. (2000a). The Washington transgender needs assessment survey. Washington, DC: The Administration for HIV and AIDS of the District of Columbia Government.

Xavier, J.M., \& Simmons, R. (2000b). The Washington transgender needs assessment survey. Washington, DC: The Administration for HIV and AIDS of the District of Columbia Government

Zimet, G. D., Powell, S. S., Farley, G. K., Werkman, S., \& Berkoff, K. A. (1990). Psychometric characteristics of the multidimensional scale of perceived social support. Journal of Personality Assessment, 55, 610-617. doi:10.1207/s15327752jpa5503\&4_17. 